\title{
Association between tobacco smoking and drug-resistant tuberculosis
}

\author{
Ming-Gui Wangl,* \\ Wei-Wei Huangl,* \\ Yu Wang' \\ Yun-Xia Zhang' \\ Miao-Miao Zhang' \\ Shou-Quan $\mathrm{Wu}^{\prime}$ \\ Andrew J Sandford ${ }^{2}$ \\ Jian-Qing $\mathrm{He}^{1}$
}

'Department of Respiratory and Critical Care Medicine, West China Hospital, Sichuan University, Chengdu, Sichuan Province, People's Republic of China; ${ }^{2}$ Centre for Heart Lung Innovation, University of British Columbia and St. Paul's Hospital, Vancouver, BC, Canada

*These authors contributed equally to this work
This article was published in the following Dove Press journal: Infection and Drug Resistance

Background: Tobacco smoking is a risk factor for tuberculosis but little is known about the relationship between tobacco smoking and drug-resistant tuberculosis (DR-TB). We undertook a systematic review and meta-analysis to quantitatively assess the association between DR-TB and tobacco smoking.

Methods: We searched for relevant studies in the Ovid MEDLINE, Embase, Cochrane Library, Web of Science, China National Knowledge Infrastructure, WANFANG, and WEIPU databases from inception to September 1, 2017. Results were expressed as odds ratios (ORs) with accompanying $95 \%$ CIs, and subgroup analyses were performed by study design, smoking type, DR-TB type, and multivariate analysis.

Results: Thirty-three studies related to tobacco smoking and DR-TB were included. We found substantial evidence that tobacco smoking is associated with an increased risk of DR-TB (OR $1.57,95 \%$ CI 1.33-1.86). Associations were also found in subgroup analyses: for multidrugresistant tuberculosis (OR 1.49, 95\% CI 1.19-1.86) and for any DR-TB (OR 1.70, 95\% CI 1.3-2.23); the pooled OR was 1.45 (95\% CI 1.11-1.90) for current smoking, 2.25 (95\% CI 1.46-3.47) for past smoking, and 1.56 (95\% CI 1.22-1.98) for smoking history; and similar ORs were also observed in study design and multivariate analysis subgroup analysis.

Conclusion: This study demonstrated that tobacco smoking is an independent risk factor for DR-TB.

Keywords: tobacco smoking, drug-resistant tuberculosis, multidrug-resistant tuberculosis, MDR-TB, meta-analysis

\section{Introduction}

Tuberculosis (TB) is a chronic infectious disease caused by the bacterium Mycobacterium tuberculosis (MTB) and remains one of the leading causes of death worldwide, despite the availability of effective anti-TB drugs. ${ }^{1}$ Globally, there were an estimated 10.4 million new TB cases and 2.0 million deaths due to the disease in $2016 .{ }^{2}$ The number of new cases increased from 9 million in 2013 to 10.4 million in $2016 .^{2,3}$

Antimicrobial resistance has become an important health concern for countries worldwide and the emergence of drug-resistant tuberculosis (DR-TB) is a great challenge for the elimination of TB. ${ }^{4}$ According to a global surveillance project from 1999 to 2002, resistance to any drug in new cases of TB was $10.2 \%$ and this number has been gradually increasing. ${ }^{5,6}$ Multidrug-resistant tuberculosis (MDR-TB), which is defined as drug resistance at least to both isoniazid and rifampicin, has spread globally since $2000{ }^{2,5,6}$ Extensively drug-resistant tuberculosis (XDR-TB) is defined
Correspondence: Jian-Qing He Department of Respiratory and Critical Care Medicine, West China Hospital, Sichuan University, No. 37, Guo Xue Alley, Chengdu, People's Republic of China

Tel +86I8980602293

Fax +868542 257I

Email Jianqhe@gmail.com 
as MDR-TB plus resistance to at least one drug in both of the two most important classes of medicines in an MDRTB regimen: fluoroquinolones and second-line injectable agents (amikacin, capreomycin, or kanamycin). ${ }^{2}$ The World Health Organization (WHO) estimates that $4 \%$ of new cases and $19 \%$ of previously treated TB cases were MDR-TB or rifampicin-resistant tuberculosis (RR-TB) in 2016, and almost half (47\%) of these cases were in India, China, and the Russian Federation. ${ }^{2}$ Globally, nearly $20 \%$ of MDR-TB/ RR-TB cases have resistance to any fluoroquinolone, while $6 \%$ of MDR-TB cases are XDR-TB. ${ }^{2}$ Unlike the majority of TB patients worldwide who can be cured with a 6 month effective first-line drug treatment, ${ }^{7}$ cases of DR-TB such as isoniazid-resistant TB, RR-TB, and MDR-TB require long-term treatment and the therapy is less effective. The treatment of MDR-TB is extremely challenging owing to the complexity of chemotherapy regimens, the toxicity of alternative drugs, and the high cost of these drugs. Therefore, it is particularly important to identify the risk factors associated with DR-TB.

Several risk factors have been considered for DR-TB. ${ }^{8-11}$ Previous treatment ranks as the strongest and most frequent determinant of DR-TB, ${ }^{8,10}$ and diabetes mellitus is also considered as an independent risk factor, especially for primary MDR-TB. ${ }^{9}$ Other factors include HIV infection, younger age, and being foreign born. ${ }^{8,11-13}$

The Global Adult Tobacco Survey (GATS) found that in 2015 there were 879 million current tobacco users, including 721 million men and 158 million women among GATS countries. ${ }^{14}$ There is substantial evidence to suggest that tobacco smoking is associated with TB infection and disease: ${ }^{15-18}$ smokers have two-fold increased risk of TB infection and active TB. ${ }^{16,17}$ Maurya et $\mathrm{al}^{19}$ found that active smoking increases the risk of extrapulmonary TB. Cigarette smoking was not only strongly associated with an increased risk of TB, but also associated with the recurrence and severity of pulmonary TB. ${ }^{18,20,21}$

Since both tobacco smoking and DR-TB are global problems, the association between tobacco smoking and DR-TB has attracted much attention from researchers. However, previous studies on the association between tobacco smoking and DR-TB were varied in regard to geographic region, ethnicity, and study design. Moreover, epidemiological data on this association have not been systematically reviewed. Therefore, we conducted a meta-analysis to determine whether tobacco smoking was an independent risk factor for DR-TB, and our results may help to guide health interventions.

\section{Methods}

This systematic review was conducted according to the Preferred Reporting Items for Systematic Reviews and MetaAnalyses (PRISMA) guidelines.

\section{Search strategies}

We searched the Ovid MEDLINE, Embase, Cochrane Library, Web of Science, China National Knowledge Infrastructure, WANFANG, and WEIPU databases to identify all published articles that evaluated the association between tobacco smoking and the risk of DR-TB, from their inception until September 16, 2017. The search terms were used as follows: "smok*" or "smoking" or "cigarette" or "tobacco" in combination with "drug-resistant tuberculosis" or "multidrug resistant tuberculosis" or "extensively drug resistant tuberculosis." The following criteria were used for selecting studies in the meta-analysis: 1) the study included patients with a diagnosis of TB; 2 ) the study evaluated the association between tobacco smoking and DR-TB; 3) the study design was cross-sectional, case-control, or cohort; and 4) adjusted odds ratios (ORs) or crude ORs and 95\% CIs were reported or could be calculated. In addition, the following exclusion criteria were used: 1) abstracts or reviews; 2) studies on children aged $<15$ years; 3 ) studies conducted on animal models or not reporting the exposures/outcomes of interest; 4) repeated or overlapping publications; and 5) studies not in English or Chinese. For duplicate or overlapping publications, the study with the largest sample size or the latest to be published was included.

\section{Data extraction and definitions}

Two independent authors (Ming-Gui Wang and Yun-Xia Zhang) checked all potentially relevant studies and tried to reach a consensus on all items. Any disagreement was assessed by a third author (Miao-Miao Zhang). The following data were extracted from each study: first author, year of publication, location of the study population, age, study design, type of DR-TB (any DR-TB, M/XDR-TB), adjusted OR (or crude OR), and 95\% CI. Any DR-TB was defined as MTB strains that show resistance to at least one of the anti-TB drugs, including monoresistant TB, polyresistant TB (resistant to two or more antibiotics), and M/XDR-TB. MDR-TB was defined as MTB strains that show resistance at least to rifampicin and isoniazid. MDR-TB with additional resistance to any fluoroquinolone and at least one of the three injectable second-line drugs was classified as XDR-TB. 


\section{Quality assessment}

All selected studies in the meta-analysis were scored for methodological quality using the Newcastle-Ottawa Scale (NOS) (http://www.ohri.ca/programs/clinical epidemiology/ oxford.asp). This scale uses a "star system" in which a study is judged on three broad perspectives: the selection of the study groups; the comparability of the groups; and the exposure for case-control or cross-sectional studies, or the outcome for cohort studies. The maximum score was 9 points. A score of $<5$ was considered low quality, 5-7 was considered medium quality, and $>7$ was considered high quality.

\section{Statistical analysis}

Since the included studies were conducted with different study designs and populations, the pooled ORs and $95 \%$ CIs were calculated using random effects models. Subgroup analyses were performed by study design (cross-sectional, case-control, and cohort), smoking type (past smoking, current smoking, and smoking history), DR-TB type (any DR-TB and M/ XDR-TB), and multivariate analysis (Yes or No). We assessed the heterogeneity among the studies by computing values for chi-square $(Q), p$-values ( $p<0.10$ was considered statistically significant), and $I^{2}$ (values of $25 \%, 50 \%$, and $75 \%$ were considered to represent low, medium, and high heterogeneity, respectively). ${ }^{22}$ Sensitivity analysis was also performed to explore the sources of heterogeneity. The Begg rank correlation and Egger weighted regression test methods were also used to statistically assess publication bias $(p<0.05$ was considered as indicative of statistically significant publication bias). STATA version 12.0 software (STATA Corporation, College Station, TX, USA) was utilized for all statistical analyses.

\section{Results}

\section{Characteristics of studies included in the review}

A total of 726 studies were identified after the initial search (Figure 1). Of these, 663 were excluded after screening by titles and abstracts. The excluded studies were those that were duplicated papers, case reports, reviews, or unrelated studies. Of the remaining 63 articles, 12 studies were excluded

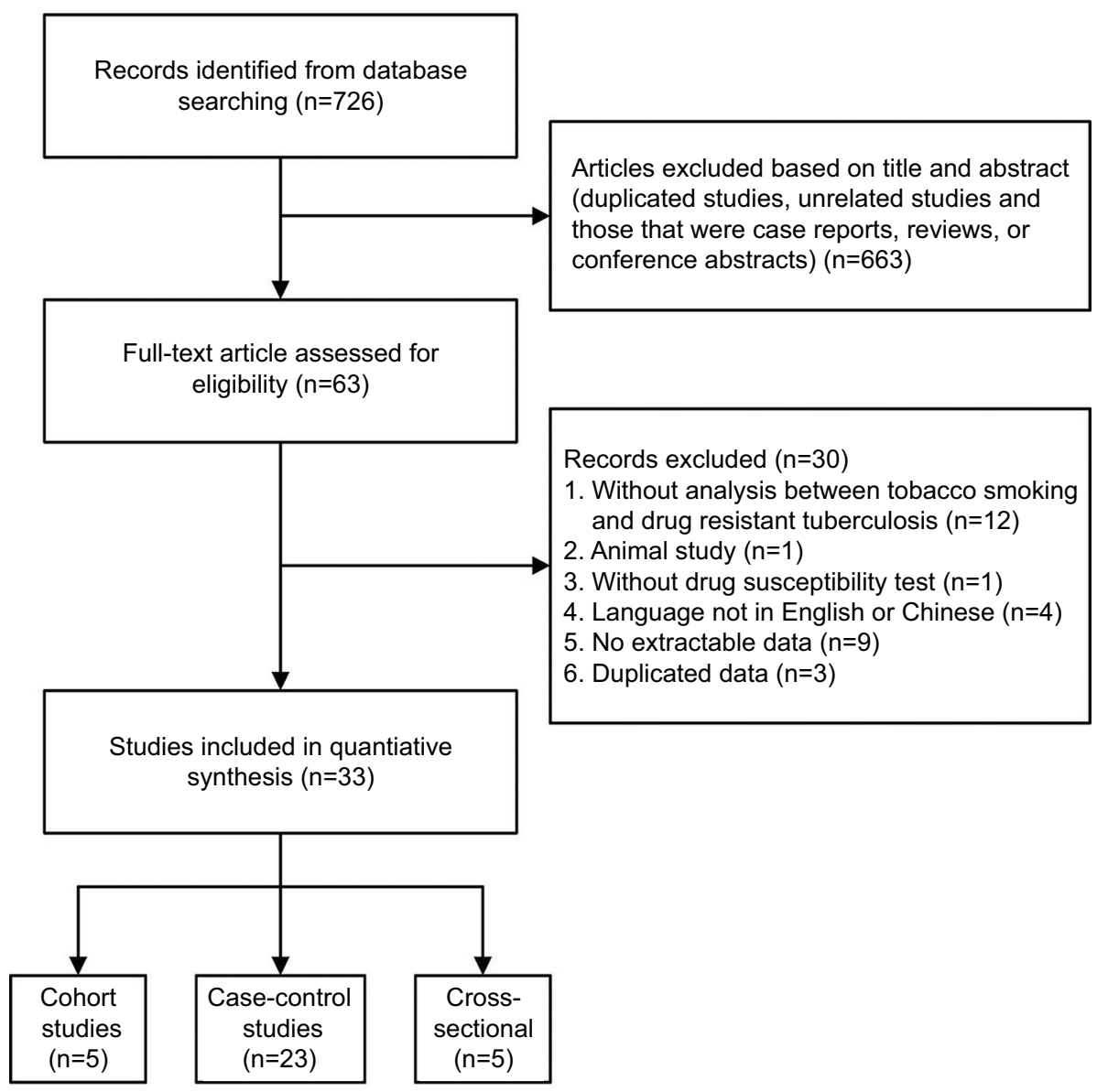

Figure I Flow diagram of included studies. 
owing to a lack of analysis of smoking and drug resistance, nine studies were excluded as they contained no extractable data, one study was conducted on animals, four studies were excluded as they were not in English or Chinese, three studies duplicated data, and one study did not include a drug susceptibility test. Finally, 33 articles were included in the systematic review and the meta-analysis. ${ }^{10,13,23-53}$ Of the 33 eligible studies, 23 were designed as case-control studies, five were cohort studies, and five were cross-sectional studies. The characteristics of all included studies are presented in Table 1 . The methodological quality was mixed as the NOS ranged from 5 to 8 , as shown in Table 1; seven articles were awarded 8 stars, 19 studies were awarded 7 stars, six articles were awarded 6 stars, and one article was awarded 5 stars.

\section{The association of smoking and drug- resistant tuberculosis}

The overall pooling result of all included studies is shown in Figure 2, and there was a significant association between DR-TB and tobacco smoking (OR 1.57, 95\% CI 1.33-1.86). We assessed heterogeneity using the $I^{2}$ statistic, and there was statistically significant heterogeneity observed among studies $\left(p<0.001, I^{2}=67.7 \%\right)$. Given the heterogeneity of the effect estimates, we conducted sensitivity analyses in which we compared pooled effect estimates for subgroups stratified on important study characteristics (Table 2). No evidence for substantial publication bias was found by either Begg's test ( $p=0.809$ ) or Egger's test ( $p=0.099)$. The Begg's funnel plot is shown in Figure 3.

Subgroup analyses were performed by study design, DR-TB type, smoking type, and whether multivariate analysis had been performed (in each analysis data were available from at least three studies for each subgroup) (Figures S1S4), and the results are summarized in Table 2. Stratification of the data by study design showed that the OR was $1.63(95 \%$ CI 1.17-2.29) for cohort studies, 1.45 (95\% CI 1.19-1.77) for case-control studies, and 2.44 (95\% CI 1.32-4.49) for cross-sectional studies. Two subgroups were used for the type of DR-TB: any DR-TB (OR 1.70, 95\% CI 1.3-2.23) and M/XDR-TB (OR 1.49, 95\% CI 1.19-1.86). Significant associations were also observed in smoking type and multivariate analysis subgroup analysis (Table 2 ). Heterogeneity was reduced in the cohort study group $\left(p=0.265, I^{2}=20.70 \%\right)$ compared with the overall pooled analysis.

\section{Discussion}

This systematic review and meta-analysis addressed the association of tobacco smoking and DR-TB using 33 selected studies. The results demonstrated that tobacco smoking was a significant independent risk factor for DR-TB regardless of study design, smoking status, and type of DR-TB. The subgroup analysis further showed that those exposed to tobacco smoking were found to have higher risks of M/XDR-TB than those who were not exposed.

To the best of our knowledge, this is the first metaanalysis to evaluate the association between tobacco smoking and DR-TB. Previous reviews had examined the association of tobacco smoking and TB, and the overall pooled summary data indicate that tobacco smoking is associated with an increased risk of TB infection and TB disease. ${ }^{15,17,18}$ Active smoking was considered as a risk factor for TB recurrence and increased mortality due to TB. ${ }^{16,17}$ Smokers were also found to be at higher risk of extrapulmonary TB than nonsmokers. ${ }^{19}$ However, whether tobacco smoking is associated with DR-TB had not been systematically reviewed previously.

TB patients who had a history of smoking exposure (regardless of whether they were current smokers or past smokers) were 1.57 times more likely to develop DR-TB compared with non-smoker TB cases. Our subgroup analyses indicated that current smokers had a 1.45 -fold and past smokers had a 2.25-fold increased risk of DR-TB. Previous studies indicated that TB patients who are smokers are less likely to complete anti-TB treatment, ${ }^{54,55}$ which may lead to poor treatment outcome. It has been reported that $16.7 \%$ of unsuccessful treatment outcomes in Chinese patients were attributable to smoking. ${ }^{56}$ Improving the treatment compliance of patients with $\mathrm{TB}$ is an effective way to reduce DR-TB and increase the cure rate. ${ }^{56-58}$ Measures to promote smoking cessation may be an effective way to reduce DR-TB, TB relapse, and secondary transmission. ${ }^{56,59}$

Another important finding of our study is the association between M/XDR-TB and tobacco smoking. The pooled risk of MDR-TB was 1.45 times higher in smokers than in non-smokers. Previous treatment, HIV infection, diabetes mellitus, low education, low income, and alcohol abuse have previously been associated with MDR-TB. ${ }^{8,9,11,58}$ The WHO has estimated that only $54 \%$ of patients with MDR/RR-TB and $30 \%$ of those with XDR-TB had a successful treatment outcome. ${ }^{2}$ Owing to the poor outcome of $\mathrm{M} / \mathrm{XDR}-\mathrm{TB}$ treatment, it is important to reduce the occurrence of $\mathrm{M} / \mathrm{XDR}-\mathrm{TB}$. Our findings suggest that, in addition to the usual benefits of smoking cessation, TB patients may benefit by reducing their risk of developing M/XDR-TB. 


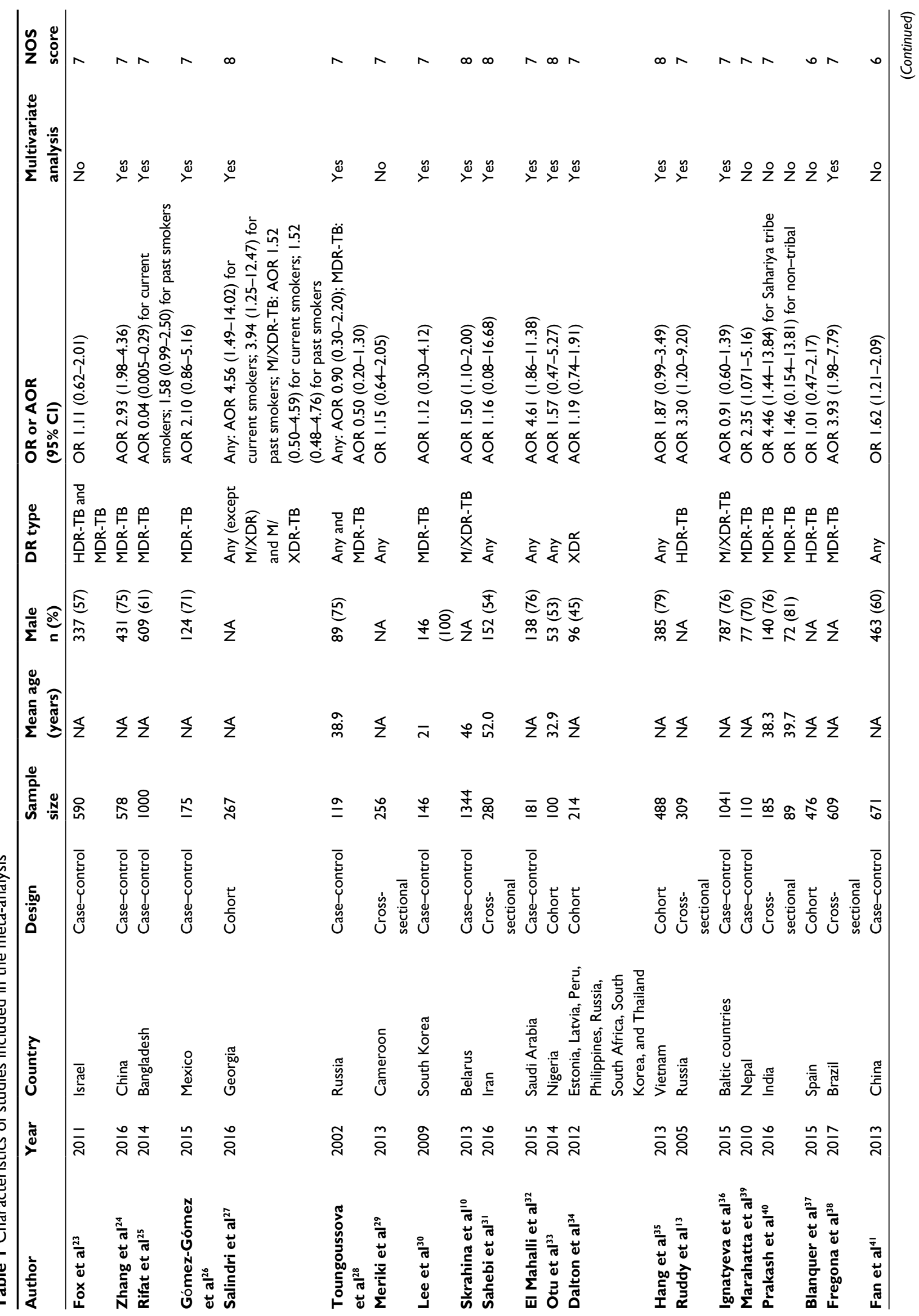




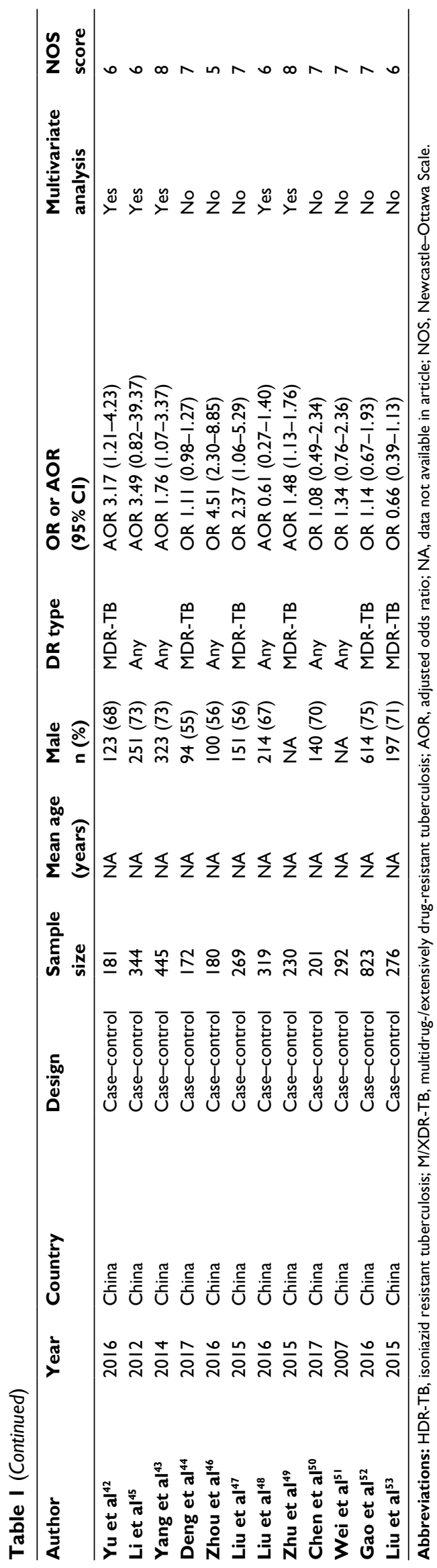

\section{Heterogeneity analysis}

The test for heterogeneity was statistically significant $\left(I^{2}=67.7 \%, p<0.001\right)$, indicating that there was considerable heterogeneity between studies. Unfortunately, we did not find any specific study that contributed a large portion of the heterogeneity in sensitivity analyses. Subgroup analyses showed that there was a significantly increased risk of DR-TB among smokers regardless of outcome definition (M/XDRTB versus any DR-TB), type of study, smoking status, or type of analysis. As shown in Table 2, the heterogeneity is mainly from study design and smoking type. Heterogeneity was low in the cohort studies $\left(I^{2}=20.70 \%, p=0.265\right)$ but high in case-control studies $\left(I^{2}=73.80 \%, p<0.001\right)$, most likely attributable to the quality of study design. When pooled estimates of studies grouped by the smoking type were compared, the heterogeneity was highest in the smoking history group $\left(I^{2}=70.10 \%, p<0.001\right)$, which did not distinguish between current smoking and past smoking. Although stratification by these study-specific variables did not fully explain the heterogeneity in the study, we consistently found a higher risk of DR-TB in TB patients with a smoking habit.

\section{Limitations of the study}

It is necessary to point out that although most of our included studies scored as high quality using the NOS, there are several potential limitations to this study. First, in this meta-analysis we only included studies published in English or Chinese, which may have resulted in a lack of data for four studies published in other languages, (Russian, Spanish, and Japanese). Although we failed to read the full text of these studies, associations between smoking and drug resistance could be discerned from the abstract of a study published in Russian, ${ }^{60}$ and another in Spanish. ${ }^{61}$ Second, we included data from different study designs, which may have led to the heterogeneity of the results. However, the similar positive association detected between smoking and DR-TB in cohort study subgroups, which are more liable to prove a cause-and-effect relationship than case-control and cross-sectional studies, reinforces our conclusion. Third, the assessment of tobacco smoking relied on self-reported behavior, which may not have been accurate because of recall error among TB patients. Furthermore, some studies did not distinguish between current smokers and past smokers, which may have led to inaccurate conclusions and contributed to the heterogeneity of the results. Fourth, studies employing both univariate and multivariate analysis were included. Univariate analysis may be influenced by other factors such as alcohol use, previous treatment of TB, primary or secondary DR, and diabetes. However, our results found 


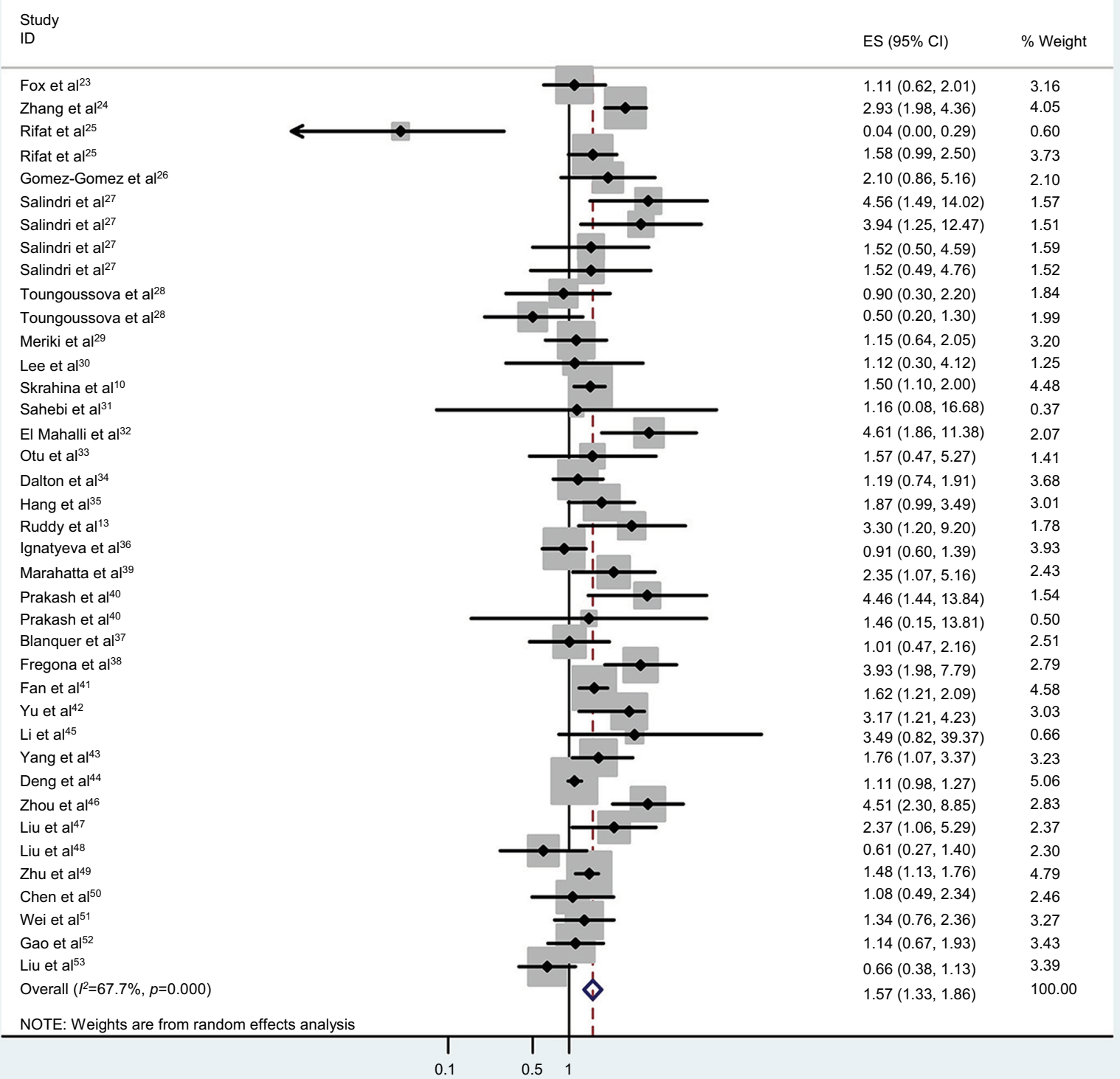

Figure 2 Forest plot of ORs assessing the association between tobacco smoking and drug-resistant tuberculosis.

Abbreviations: $\mathrm{ES}$, effect size; OR, odds ratio.

Table 2 Subgroup analyses

\begin{tabular}{|c|c|c|c|c|}
\hline Measure or outcome & $\begin{array}{l}\text { Study characteristics } \\
\text { (number of studies) }\end{array}$ & Pooled OR & $95 \% \mathrm{Cl}$ & $I^{2}(\%)$ \\
\hline \multirow[t]{3}{*}{ Type of study } & Cohort studies (5) & 1.63 & I.17-2.29 & 20.70 \\
\hline & Case-control studies (25) & 1.45 & I.19-1.77 & 73.80 \\
\hline & Cross-sectional (5) & 2.44 & $1.32-4.49$ & 49.40 \\
\hline \multirow[t]{2}{*}{ Type of DR-TB } & Any DR-TB (15) & 1.70 & $1.30-2.23$ & 52.40 \\
\hline & M/XDR-TB (I8) & 1.49 & $1.19-1.86$ & 58.25 \\
\hline \multirow[t]{3}{*}{ Type of smoking } & Smoking history (14) & 1.56 & $1.22-1.98$ & 70.10 \\
\hline & Current smoking (18) & 1.45 & $1.11-1.90$ & 63.30 \\
\hline & Past smoking (3) & 2.25 & $1.46-3.47$ & 43.50 \\
\hline \multirow[t]{2}{*}{ Multivariate analysis } & Yes $(20)$ & 1.68 & $1.33-2.12$ & 65.20 \\
\hline & No (13) & 1.41 & $1.11-1.80$ & 64.60 \\
\hline
\end{tabular}

Abbreviations: DR-TB, drug resistant tuberculosis; M/XDR-TB, multidrug- or extensively drug-resistant tuberculosis; OR, odds ratio. 


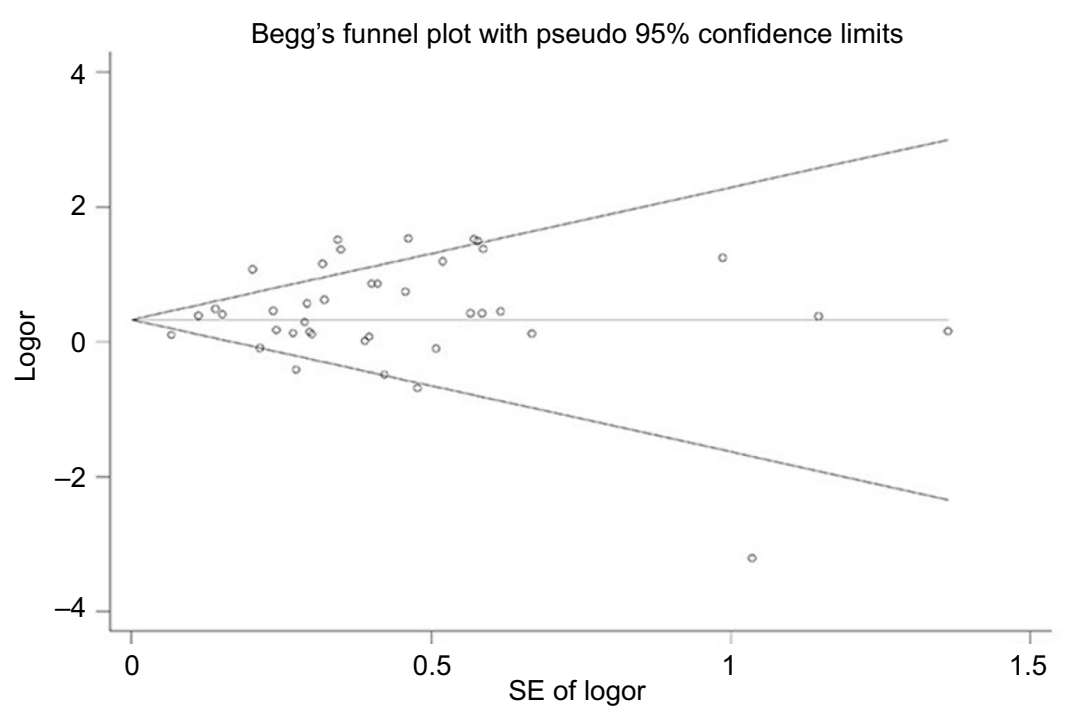

Figure 3 Funnel plot for publication bias.

Abbreviation: logor, natural log of odds ratio.

similar ORs and heterogeneity between the univariate and multivariate analysis groups, which strengthens the reliability of our conclusion. Finally, the laboratory conditions and technical proficiency of medical staff vary in different areas, and these factors may limit the accuracy of DR testing.

\section{Conclusion}

Our meta-analysis indicates that tobacco smoking was positively and significantly associated with DR-TB. Subgroup analysis also showed that tobacco smoking was an independent risk factor for $\mathrm{M} / \mathrm{XDR}-\mathrm{TB}$. These findings suggest that DR-TB control might benefit from interventions aimed at reducing tobacco use. In other words, additional efforts should be made to encourage TB patients to quit smoking once they are diagnosed.

\section{Acknowledgments}

This work was supported by the Research Fund for the Doctoral Program of Higher Education of China (RFDP grant number 20130181110068), the National Natural Science Foundation of China (grant numbers 81170042 and 81370121), and the National Scientific and Technological Major Project of China (grant number 2012ZX10004-901).

\section{Disclosure}

The authors report no conflicts of interest in this work.

\section{References}

1. Lawn SD, Zumla AI. Tuberculosis. Lancet. 2011;378(9785):57-72.

2. World Health Organization. Global Tuberculosis Report 2017. Geneva: World Health Organization; 2017.

3. World Health Organization. Global Tuberculosis Report 2014. Geneva: World Health Organization; 2014.
4. General Assembly of the United Nations. High-level meeting on antimicrobial resistance. 2016. Available from: www.un.org/ pga/71/2016/09/21/press-release-hl-meeting-on-antimicrobial-resistance. Accessed November 7, 2016.

5. Wright A, Zignol M, Van Deun A, et al. Epidemiology of antituberculosis drug resistance 2002-07: an updated analysis of the Global Project on Anti-Tuberculosis Drug Resistance Surveillance. Lancet. 2009;373(9678):1861-1873.

6. Aziz MA, Wright A, Laszlo A, et al. Epidemiology of antituberculosis drug resistance (the Global Project on Anti-tuberculosis Drug Resistance Surveillance): an updated analysis. Lancet. 2006;368(9553):2142-2154.

7. World Health Organization. Treatment of tuberculosis: guidelines. 4th edn. WHO/HTM/TB/2009.420. 2009. Available from: http://whqlibdoc.who.int/publications/2010/9789241547833_eng.pdf. Accessed November 7, 2016.

8. Faustini A, Hall AJ, Perucci CA. Risk factors for multidrug resistant tuberculosis in Europe: a systematic review. Thorax. 2006;61(2):158-163.

9. Liu Q, Li W, Xue M, et al. Diabetes mellitus and the risk of multidrug resistant tuberculosis: a meta-analysis. Sci Rep. 2017;7(1):1090.

10. Skrahina A, Hurevich H, Zalutskaya A, et al. Multidrug-resistant tuberculosis in Belarus: the size of the problem and associated risk factors. Bull World Health Organ. 2013;91(1):36-45.

11. Mesfin YM, Hailemariam D, Biadgilign S, Kibret KT. Association between HIV/AIDS and multi-drug resistance tuberculosis: a systematic review and meta-analysis. PLoS One. 2014;9(1):e82235.

12. Long R, Langlois-Klassen $D$. Increase in multidrug-resistant tuberculosis (MDR-TB) in Alberta among foreign-born persons: implications for tuberculosis management. Can J Public Health. 2013;104(1):e22-e27.

13. Ruddy M, Balabanova Y, Graham C, et al. Rates of drug resistance and risk factor analysis in civilian and prison patients with tuberculosis in Samara Region, Russia. Thorax. 2005;60(2):130-135.

14. The GATS Atlas. Global Adult Tobacco Survey 2015. Available from: http://www.who.int/tobacco/publications/surveillance/gatstlas/en/. Accessed November 07, 2017.

15. den Boon S, van Lill SW, Borgdorff MW, et al. Association between smoking and tuberculosis infection: a population survey in a high tuberculosis incidence area. Thorax. 2005;60(7):555-557.

16. Lin HH, Ezzati M, Chang HY, Murray M. Association between tobacco smoking and active tuberculosis in Taiwan: prospective cohort study. Am J Respir Crit Care Med. 2009;180(5):475-480.

17. Bates MN, Khalakdina A, Pai M, Chang L, Lessa F, Smith KR. Risk of tuberculosis from exposure to tobacco smoke: a systematic review and meta-analysis. Arch Intern Med. 2007;167(4):335-342. 
18. Lin HH, Ezzati M, Murray M. Tobacco smoke, indoor air pollution and tuberculosis: a systematic review and meta-analysis. PLoS Med. 2007;4(1):e20.

19. Maurya V, Vijayan VK, Shah A. Smoking and tuberculosis: an association overlooked. Int J Tuberc Lung Dis. 2002;6(11):942-951.

20. Jayes L, Haslam PL, Gratziou CG, et al. SmokeHaz: Systematic Reviews and Meta-analyses of the Effects of Smoking on Respiratory Health. Chest. 2016;150(1):164-179.

21. Underner M, Perriot J, Peiffer G, Meurice JC, Dautzenberg B. [Smoking and adherence to anti-tuberculosis treatment]. Rev Mal Respir. 2016;33(2):128-144

22. Rücker G, Schwarzer G, Carpenter JR, Schumacher M. Undue reliance on $\mathrm{I}(2)$ in assessing heterogeneity may mislead. BMC Med Res Methodol. 2008;8:79.

23. Fox L, Kramer MR, Haim I, Priess R, Metvachuk A, Shitrit D. Comparison of isoniazid monoresistant tuberculosis with drug-susceptible tuberculosis and multidrug-resistant tuberculosis. Eur J Clin Microbiol Infect Dis. 2011;30(7):863-867.

24. Zhang C, Wang Y, Shi G, et al. Determinants of multidrug-resistant tuberculosis in Henan province in China: a case control study. BMC Public Health. 2016;16:42.

25. Rifat M, Milton AH, Hall J, et al. Development of multidrug resistant tuberculosis in Bangladesh: a case-control study on risk factors. PLoS One. 2014;9(8):e105214.

26. Gómez-Gómez A, Magaña-Aquino M, López-Meza S, et al. Diabetes and Other Risk Factors for Multi-drug Resistant Tuberculosis in a Mexican Population with Pulmonary Tuberculosis: Case Control Study. Arch Med Res. 2015;46(2):142-148.

27. Salindri AD, Kipiani M, Kempker RR, et al. Diabetes Reduces the Rate of Sputum Culture Conversion in Patients With Newly Diagnosed Multidrug-Resistant Tuberculosis. Open Forum Infect Dis. 2016;3(3):ofw126.

28. Toungoussova S, Caugant DA, Sandven P, Mariandyshev AO, Bjune G. Drug resistance of Mycobacterium tuberculosis strains isolated from patients with pulmonary tuberculosis in Archangels, Russia. Int JTuberc Lung Dis. 2002;6(5):406-414.

29. Meriki HD, Tufon KA, Atanga PN, et al. Drug resistance profiles of Mycobacterium tuberculosis complex and factors associated with drug resistance in the Northwest and Southwest Regions of Cameroon. PLoS One. 2013;8(10): 77410.

30. Lee SW, Jeon K, Kim KH, Min KH. Multidrug-resistant pulmonary tuberculosis among young Korean soldiers in a communal setting. J Korean Med Sci. 2009;24(4):592-595.

31. Sahebi L, Ansarin K, Mohajeri P, et al. Patterns of Drug Resistance Among Tuberculosis Patients in West and Northwestern Iran. Open Respir Med J. 2016;10:29-35.

32. El Mahalli AA, Al-Qahtani MF. Predictors of drug resistance in tuberculosis patients in the Eastern Province, Saudi Arabia. J Egypt Public Health Assoc. 2015;90(1):24-28.

33. Otu A, Umoh V, Habib A, Ansa V. Prevalence and clinical predictors of drug-resistant tuberculosis in three clinical settings in Calabar, Nigeria. Clin Respir J. 2014;8(2):234-239.

34. Dalton T, Cegielski P, Akksilp S, et al. Prevalence of and risk factors for resistance to second-line drugs in people with multidrug-resistant tuberculosis in eight countries: a prospective cohort study. Lancet 2012;380(9851):1406-1417.

35. Hang NT, Maeda S, Lien LT, et al. Primary drug-resistant tuberculosis in Hanoi, Viet Nam: present status and risk factors. PLoS One. 2013;8(8):e71867.

36. Ignatyeva O, Balabanova Y, Nikolayevskyy V, et al. Resistance profile and risk factors of drug resistant tuberculosis in the Baltic countries. Tuberculosis (Edinb). 2015;95(5):581-588.

37. Blanquer R, Rodrigo T, Casals M, et al. Resistance to first-line antituberculosis drugs in Spain, 2010-2011. RETUBES Study. Arch Bronconeumol. 2015;51(1):24-30.

38. Fregona G, Cosme LB, Moreira CMM, et al. Risk factors associated with multidrug-resistant tuberculosis in Espírito Santo, Brazil. Rev Saude Publica. 2017;51(0):41.
39. Marahatta SB, Kaewkungwal J, Ramasoota P, Singhasivanon P. Risk factors of multidrug resistant tuberculosis in central Nepal: a pilot study. Kathmandu Univ Med J (KUMJ). 2010;8(32):392-397.

40. Prakash R, Kumar D, Gupta VK, et al. Status of multidrug resistant tuberculosis (MDR-TB) among the Sahariya tribe of North Central India. J Infect Public Health. 2016;9(3):289-297.

41. Fan D, Chen G, Wu S, Yu D. Analysis of drug resistance of mycobacterium tuberculosis among 723 tuberculosis patients. Zhejiang Preventive Medicine. 2013;25(12):42-43. Available from: http://qikan.cqvip.com/ article/detail.aspx?id=48001561\&from=zk_search. Accessed May 02, 2018.

42. Yu S, Mei X, Kan X, Fang X, Bao X. Risk factors of multidrug-resistant tuberculosis in Anhui Province: A case-control study. Chin J Dis Control Prev. 2016;20(10):1026-1028. Available from: http:/qikan.cqvip. com/article/detail.aspx?id=670542634\&from=zk_search. Accessed May 02, 2018.

43. Yang J, Huang L, Zhou L, Geng W. Study on risk factors of acquired drug resistance of tuberculosis in Guangxi. Journal of Tuberculosis and Lung Health . 2014;3(1):29-34. Available from: http:/qikan.cqvip. com/article/read.aspx?id=1003334310\&from=article_detail. Accessed May 02, 2018.

44. Deng W, Xie X, Liu L, Xie H. A case-control study on risk factors of rural patients with multi-drug resistant tuberculosis in Xiangtan, Hunan. China Tropical Medicine. 2017;17(3):306-308.

45. Li J, Huang J, Zhou D. The logistic regression analysis of risk factors associated with drug-resistant tuberculosis. China Modern Doctor. 2012;50(7):134-135. Available from: http://qikan.cqvip.com/article/ read.aspx?id=41093727\&from=zk_search. Accessed May 02, 2018.

46. Zhou Y, Chen C, Lin Z. Analysis of the risk factors and countermeasures for drug resistance TB patients. Pract Prev Med. 2016;23(5):601-602. Available from: http://qikan.cqvip.com/article/ detail.aspx?id=668575245\&from=zk_search. Accessed May 02, 2018.

47. Liu R, Wang Y, Gao M, Wang L, Ma L. A case-control study for risk factors of multi-drug resistant tuberculosis in Qinghai area. Journal of Clinical Pulmonary Medicine. 2015;20(4):592-595. Availablr from: http://qikan.cqvip.com/article/read.aspx?id=664039091\&from=zk_ search. Accessed May 02, 2018.

48. Liu H, Rui B, Chen Y, Zhang W, Ma L. Analysis on risk factors of patients with drug resistant tuberculosis in Urumqi. Occupation and Health. 2016;32(19):2658-2660. Available from: http://qikan.cqvip. com/article/detail.aspx?id=670630926\&from=zk_search. Accessed May 02, 2018.

49. Zhu Z. Risk factors of multi-drug resistant tuberculosis of 120 cases in Xuchang. Practical Journal of Cardiac Cerebral Pneumal and Vascular Disease. 2015;23(5):082-084. Available from: http://qikan.cqvip.com/ article/read.aspx?id=665361643\&from=zk_search. Accessed May 02, 2018.

50. Chen Y, Lu J, Ma L, Liu H, Zhang W, Rui B. Drug resistance of pulmonary tuberculosis and its influencing factors in Urumqi Municipality, 2014. Pract Prev Med. 2017;24(2):168-171.

51. Wei C, Wang Q, Chen J. Study on risk factors for aquired drug resistance tuberculosis in some province. Modern Preventive Medicine. 2007;34(17):3275-3277. Available from: http://qikan.cqvip.com/article/ read.aspx?id=25333140\&from=zk_search. Accessed May 02, 2018.

52. Gao C, Liu J, Zhang R. Analysis of risk factors for multi drugresistant pulmonary tuberculosis. Jiangsu Med J. 2016;42(16):17761778. Available from: http://qikan.cqvip.com/article/detail. aspx?id=669859191\&from=zk_search. Accessed May 02, 2018.

53. Liu R, Gao M, Qin S, Ma L, Song Y. A case-control study on risk factors of multidrug-resistant pulmonary tuberculosis. Chin J Antituberc. 2015;37(8). Available from: http://new.wanfangdata.com.cn/details/ detail.do?_type=perio\&id=zgflzz201508011. Accessed May 10, 2018.

54. Lavigne M, Rocher I, Steensma C, Brassard P. The impact of smoking on adherence to treatment for latent tuberculosis infection. BMC Public Health. 2006;6:66.

55. Schneider NK, Novotny TE. Addressing smoking cessation in tuberculosis control. Bull World Health Organ. 2007;85(10):820-821. 
56. Leung CC, Yew WW, Chan CK, et al. Smoking adversely affects treatment response, outcome and relapse in tuberculosis. Eur Respir J. 2015;45(3):738-745.

57. Samman Y, Krayem A, Haidar M, et al. Treatment outcome of tuberculosis among Saudi nationals: role of drug resistance and compliance. Clin Microbiol Infect. 2003;9(4):289-294.

58. Di Gennaro F, Pizzol D, Cebola B, et al. Social determinants of therapy failure and multi drug resistance among people with tuberculosis: A review. Tuberculosis (Edinb). 2017;103:44-51.

59. Jeyashree K, Kathirvel S, Shewade HD, Kaur H, Goel S. Smoking cessation interventions for pulmonary tuberculosis treatment outcomes. Cochrane Database Syst Rev. 2016(1):CD011125.
60. Filinyuk OV, Urazova OI, Nekrasov YeV, et al. Social aspects multidrug resistant tuberculosis. [Russian]. Byulleten' sibirskoi meditsiny. 2012;11(4):167-170. Available from: http://apps.webofknowledge.com/ full_record.do?product=UA\&search_mode=GeneralSearch\&qid=1\&S $\mathrm{ID}=8 \mathrm{CGsGdO} 3 \mathrm{jX} 1 \mathrm{WugwWZ1J \& page}=1 \&$ doc $=10$.

61. Arago Galindo M, Belda Mira A, Contel AA, et al. [Anti-tuberculosis drug resistance of Mycobacterium tuberculosis in the area of the Hospital de Sagunto from 1999 to 2004]. [Spanish]. Rev Clin Esp. 2006;206(8):376-381. 


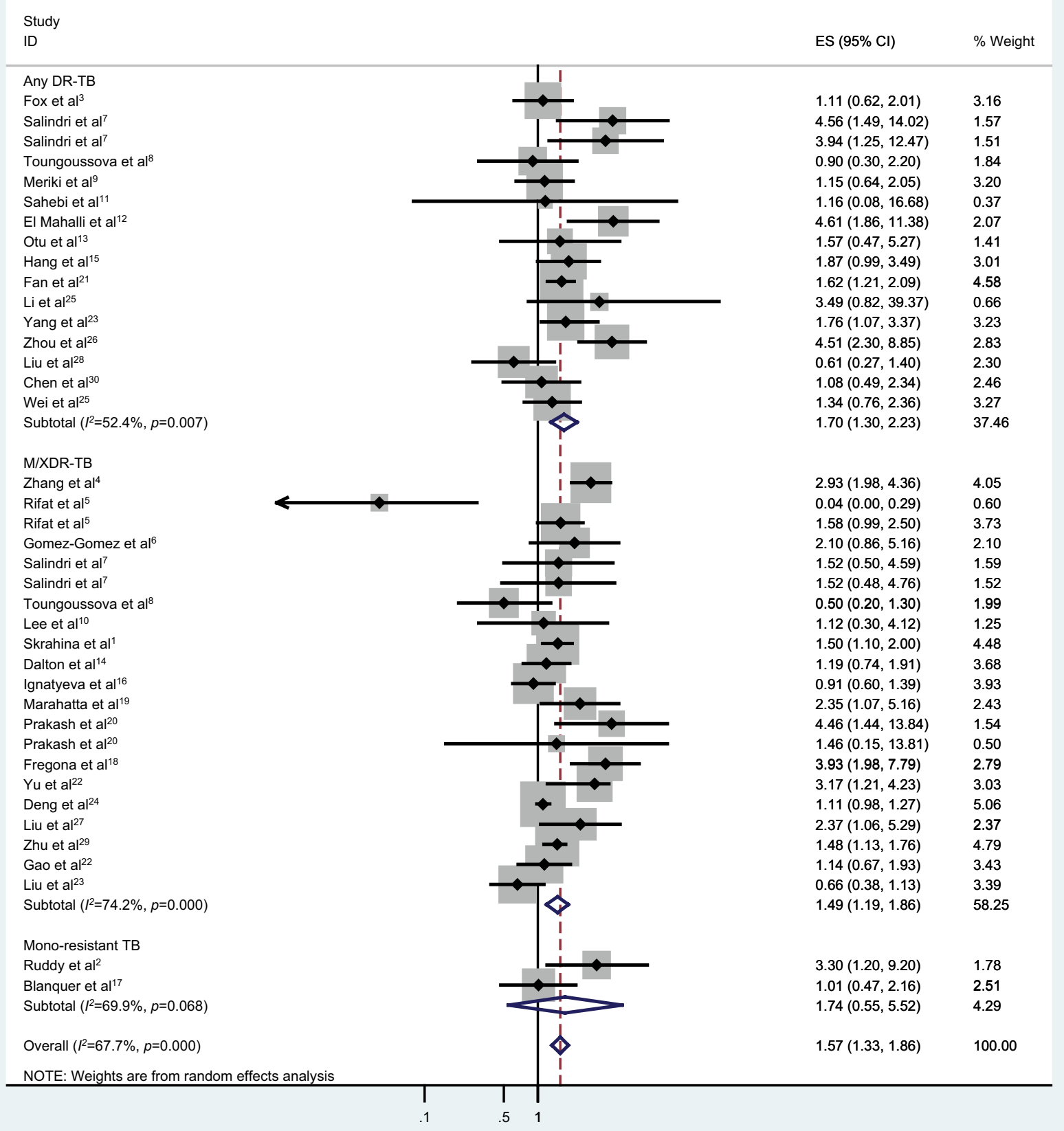

Figure S2 Subgroup analysis of DR-TB type.

Abbreviations: DR-TB, drug-resistant tuberculosis; ES, effect size; M/XDR-TB, multidrug-resistant tuberculosis. 


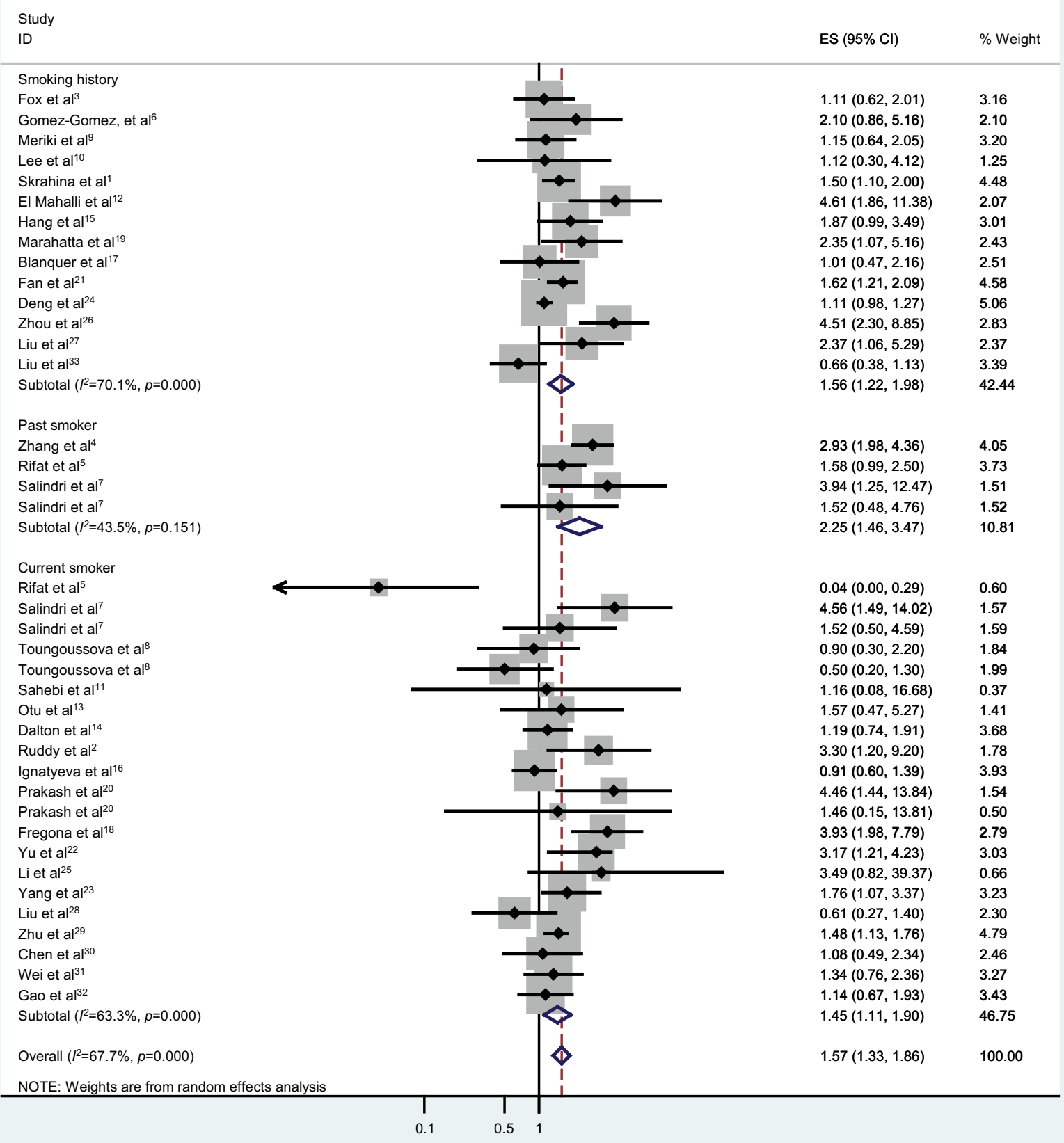

Figure S3 Subgroup analysis of smoking type.

Abbreviation: ES, effect size. 


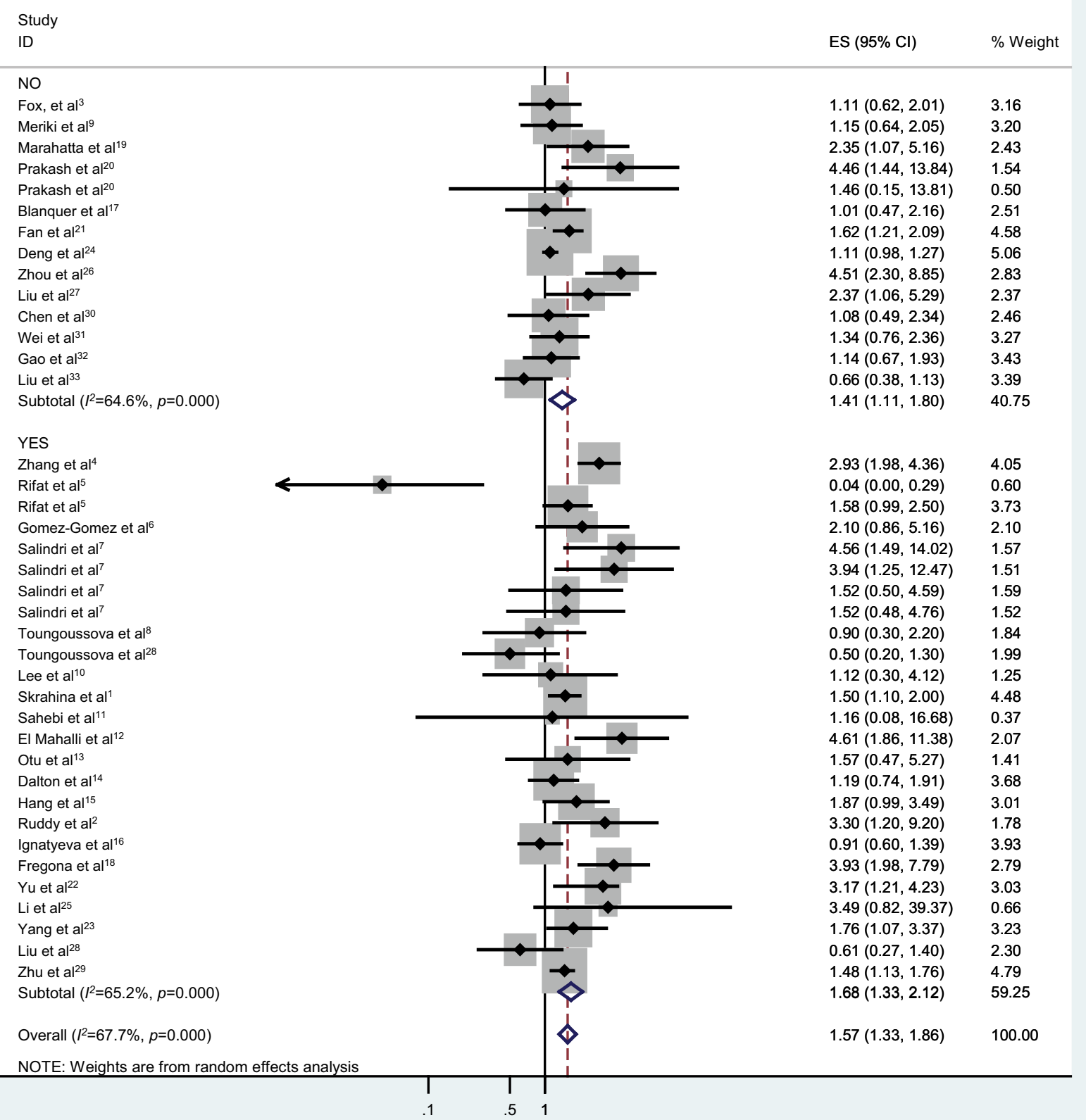

Figure S4 Subgroup analysis of OR type (YES: adjusted OR; NO: crude OR). Abbreviations: $\mathrm{ES}$, effect size; OR, odds ratio.

\section{References}

1. Skrahina A, Hurevich H, Zalutskaya A, et al. Multidrug-resistant tuberculosis in Belarus: the size of the problem and associated risk factors. Bull World Health Organ. 2013;91(1):36-45.

2. Ruddy M, Balabanova Y, Graham C, et al. Rates of drug resistance and risk factor analysis in civilian and prison patients with tuberculosis in Samara Region, Russia. Thorax. 2005;60(2):130-135.

3. Fox L, Kramer MR, Haim I, Priess R, Metvachuk A, Shitrit D. Comparison of isoniazid monoresistant tuberculosis with drug-susceptible tuberculosis and multidrug-resistant tuberculosis. Eur J Clin Microbiol Infect Dis. 2011;30(7):863-867.

4. Zhang C, Wang Y, Shi G, et al. Determinants of multidrug-resistant tuberculosis in Henan province in China: a case control study. BMC Public Health. 2016;16:42.
5. Rifat M, Milton AH, Hall J, et al. Development of multidrug resistant tuberculosis in Bangladesh: a case-control study on risk factors. PLoS One. 2014;9(8):e105214.

6. Gómez-Gómez A, Magaña-Aquino M, López-Meza S, et al. Diabetes and Other Risk Factors for Multi-drug Resistant Tuberculosis in a Mexican Population with Pulmonary Tuberculosis: Case Control Study. Arch Med Res. 2015;46(2):142-148.

7. Salindri AD, Kipiani M, Kempker RR, et al. Diabetes Reduces the Rate of Sputum Culture Conversion in Patients With Newly Diagnosed Multidrug-Resistant Tuberculosis. Open Forum Infect Dis. 2016;3(3):ofw126.

8. Toungoussova S, Caugant DA, Sandven P, Mariandyshev AO, Bjune G. Drug resistance of Mycobacterium tuberculosis strains isolated from patients with pulmonary tuberculosis in Archangels, Russia. Int J Tuberc Lung Dis. 2002;6(5):406-414. 
9. Meriki HD, Tufon KA, Atanga PN, et al. Drug resistance profiles of Mycobacterium tuberculosis complex and factors associated with drug resistance in the Northwest and Southwest Regions of Cameroon. PLoS One. 2013;8(10): 77410 .

10. Lee SW, Jeon K, Kim KH, Min KH. Multidrug-resistant pulmonary tuberculosis among young Korean soldiers in a communal setting. $J$ Korean Med Sci. 2009;24(4):592-595.

11. Sahebi L, Ansarin K, Mohajeri P, et al. Patterns of Drug Resistance Among Tuberculosis Patients in West and Northwestern Iran. Open Respir Med J. 2016;10:29-35.

12. El Mahalli AA, Al-Qahtani MF. Predictors of drug resistance in tuberculosis patients in the Eastern Province, Saudi Arabia. J Egypt Public Health Assoc. 2015;90(1):24-28.

13. Otu A, Umoh V, Habib A, Ansa V. Prevalence and clinical predictors of drug-resistant tuberculosis in three clinical settings in Calabar, Nigeria. Clin Respir J. 2014;8(2):234-239.

14. Dalton T, Cegielski P, Akksilp S, et al. Prevalence of and risk factors for resistance to second-line drugs in people with multidrug-resistant tuberculosis in eight countries: a prospective cohort study. Lancet. 2012;380(9851):1406-1417.

15. Hang NT, Maeda S, Lien LT, et al. Primary drug-resistant tuberculosis in Hanoi, Viet Nam: present status and risk factors. PLoS One. 2013;8(8):e71867.

16. Ignatyeva $\mathrm{O}$, Balabanova $\mathrm{Y}$, Nikolayevskyy V, et al. Resistance profile and risk factors of drug resistant tuberculosis in the Baltic countries. Tuberculosis (Edinb). 2015;95(5):581-588.

17. Blanquer R, Rodrigo T, Casals M, et al. Resistance to first-line antituberculosis drugs in Spain, 2010-2011. RETUBES Study. Arch Bronconeumol. 2015;51(1):24-30.

18. Fregona G, Cosme LB, Moreira CMM, et al. Risk factors associated with multidrug-resistant tuberculosis in Espírito Santo, Brazil. Rev Saude Publica. 2017;51(0):41.

19. Marahatta SB, Kaewkungwal J, Ramasoota P, Singhasivanon P. Risk factors of multidrug resistant tuberculosis in central Nepal: a pilot study. Kathmandu Univ Med J (KUMJ). 2010;8(32):392-397.

20. Prakash R, Kumar D, Gupta VK, et al. Status of multidrug resistant tuberculosis (MDR-TB) among the Sahariya tribe of North Central India. J Infect Public Health. 2016;9(3):289-297.

21. Fan D, Chen G, Wu S, Yu D. Analysis of drug resistance of mycobacterium tuberculosis among 723 tuberculosis patients. Zhejiang Preventive Medicine. 2013;25(12):42-43. Available from: http:/qikan.cqvip.com/ article/detail.aspx?id=48001561\&from=zk_search. Accessed May 02, 2018.

22. Yu S, Mei X, Kan X, Fang X, Bao X. Risk factors of multidrug-resistant tuberculosis in Anhui Province: A case-control study. Chin J Dis Control Prev. 2016;20(10):1026-1028. Available from: http://qikan.cqvip.com/ article/detail.aspx?id=670542634\&from=zk_search. Accessed May 02, 2018.
23. Yang J, Huang L, Zhou L, Geng W. Study on risk factors of acquired drug resistance of tuberculosis in Guangxi. Journal of Tuberculosis and Lung Health. 2014;3(1):29-34. Available from: http://qikan.cqvip.com/ article/read.aspx?id=1003334310\&from=article_detail. Accessed May $02,2018$.

24. Deng W, Xie X, Liu L, Xie H. A case-control study on risk factors of rural patients with multi-drug resistant tuberculosis in Xiangtan, Hunan. China Tropical Medicine. 2017;17(3):306-308.

25. Li J, Huang J, Zhou D. The logistic regression analysis of risk factors associated with drug-resistant tuberculosis. China Modern Doctor. 2012;50(7):134-135. Available from: http://qikan.cqvip.com/article/ read.aspx?id=41093727\&from=zk_search. Accessed May 02, 2018.

26. Zhou Y, Chen C, Lin Z. Analysis of the risk factors and countermeasures for drug resistance TB patients. Pract Prev Med. 2016;23(5):601-602. Available from: http://qikan.cqvip.com/article/ detail.aspx?id=668575245\&from=zk_search. Accessed May 02, 2018.

27. Liu R, Wang Y, Gao M, Wang L, Ma L. A case-control study for risk factors of multi-drug resistant tuberculosis in Qinghai area. J ClinPul Med. 2015;20(4):592-595. Availablr from: http://qikan.cqvip.com/ article/read.aspx?id=664039091\&from=zk_search. Accessed May 02, 2018.

28. Liu H, Rui B, Chen Y, Zhang W, Ma L. Analysis on risk factors of patients with drug resistant tuberculosis in Urumqi. Occup Health. 2016;32(19):2658-2660. Available from: http://qikan.cqvip.com/article/ detail.aspx?id=670630926\&from=zk_search. Accessed May 02, 2018

29. Zhu Z. Risk factors of multi-drug resistant tuberculosis of 120 cases in Xuchang. Practical Journal of Cardiac Cerebral Pneumal and Vascular Disease. 2015;23(5):082-084. Available from: http://qikan.cqvip.com/ article/read.aspx?id=665361643\&from $=$ zk_search. Accessed May 02, 2018.

30. Chen Y, Lu J, Ma L, Liu H, Zhang W, Rui B. Drug resistance of pulmonary tuberculosis and its influencing factors in Urumqi Municipality, 2014. Pract Prev Med. 2017;24(2):168-171.

31. Wei C, Wang Q, Chen J. Study on risk factors for aquired drug resistance tuberculosis in some province. Modern Preventive Medicine. 2007;34(17):3275-3277. Available from: http://qikan.cqvip.com/article/ read.aspx?id=25333140\&from=zk_search. Accessed May 02, 2018.

32. Gao C, Liu J, Zhang R. Analysis of risk factors for multi drugresistant pulmonary tuberculosis. Jiangsu Med J. 2016;42(16):17761778. Available from: http://qikan.cqvip.com/article/detail. aspx?id=669859191\&from=zk_search. Accessed May 02, 2018.

33. Liu R, Gao M, Qin S, Ma L, Song Y. A case-control study on risk factors of multidrug-resistant pulmonary tuberculosis. Chin J Antituberc. 2015;37(8). Available from: http://new.wanfangdata.com.cn/details/ detail.do?_type=perio\&id=zgflzz201508011. Accessed May 10, 2018
Infection and Drug Resistance

\section{Publish your work in this journal}

Infection and Drug Resistance is an international, peer-reviewed openaccess journal that focuses on the optimal treatment of infection (bacterial, fungal and viral) and the development and institution of preventive strategies to minimize the development and spread of resistance. The journal is specifically concerned with the epidemiology of antibiotic

\section{Dovepress}

resistance and the mechanisms of resistance development and diffusion in both hospitals and the community. The manuscript management system is completely online and includes a very quick and fair peerreview system, which is all easy to use. Visit http://www.dovepress.com/ testimonials.php to read real quotes from published authors. 